\title{
Editorial: Indicators of Child Well-Being in the Context of Small Areas
}

\author{
Claudia J. Coulton • Jill E. Korbin • \\ James McDonell
}

Accepted: 20 April 2009 /Published online: 13 May 2009

(C) Springer Science + Business Media B.V. 2009

The six papers from five continents in this collection reflect growing awareness of the importance of small areas for understanding the context of child well-being. The papers point to the need for concerted efforts to capture the contexts in which children and families live and the need for innovative approaches to these issues. The papers lend themselves to discussion of critical questions in the relationship between context and child well being.

These papers highlight why those interested in child well-being should direct attention to small area indicators. Small areas (for example, villages, neighborhoods and communities) are the immediate context in which families and children live. Attention to small areas allows for a more nuanced and contextual understanding of deprivation, social exclusion, and disparities than is possible in analyses at the state or national level. At a state or national level, differences may be muted in the portrayal child indicators as rates on measures of well-being. Overall rates of infant mortality in the United States, as one example, may mask important sub-population differences. Comparisons across small areas can reveal disparities in child wellbeing as well as point to strategies to reduce place-based inequalities.

The papers in this special issue also push the field to identify more precisely what is meant by a small area. Defined differently as towns, census tracts, block groups or other administrative areas, the papers in this special issue take different approaches

\section{J. Coulton}

Mandel School of Applied Social Sciences, Case Western Reserve University, Center on Urban Poverty and Community Development, 10900 Euclid Ave., Cleveland, OH 44106, USA e-mail: claudia.coulton@case.edu

\section{J. E. Korbin $(\bowtie)$}

College of Arts and Sciences, Case Western Reserve University, Schubert Center for Child Studies, 10900 Euclid Ave., Cleveland, OH 44106-7179, USA

e-mail: jill.korbin@case.edu

J. McDonell

Clemson University, Institute on Family and Neighborhood Life, 158 Poole, Clemson, SC 29634, USA

e-mail: jmcdnll@exchange.clemson.edu 
based largely on the availability of administrative data and the geo-political reality of the settings. The papers call for increased efforts or innovative approaches to understanding the relevance and meaning of small areas. Moving beyond administrative boundaries, Spilsbury, Korbin and Coulton's contribution considers child and parent definitions of neighborhood parameters in defining neighborhoods and thereby understanding the context in which child indicators are measured. Adding further depth to the usual data sources for small areas, McDonell, similar to work by Sampson and colleagues in Chicago, employed observational ratings to assess neighborhoods.

The papers in this issue also demonstrate that indicators of child well-being can be usefully employed to reflect variability of contexts presented by small areas. Small area research allows for understanding the processes that contribute to indicators of child-well being. The contribution by McNamara, Tanton, Daly and Harding in Australia found indicators at the small area level particularly useful for identifying patterns of persistence and change in child social exclusion. Similarly, in Barnes, Noble, Wright and Dawes' study in South Africa, child indicators were usefully employed at the small area level to understand variability in child wellbeing. These two papers, plus those by Bradshaw and colleagues in England and Vollmer-Larsen Niclassen and Kohler in Greenland point to the limitations of available data and the need to further develop such indices.

Importantly, indices of child well-being at the small area level have implications for linking research, practice and policy. At the small area level, there is potential for the application of data to solutions as the data are made available to communities as well as to researchers. Bringing indicators to the small area level, such as community or neighborhood, has the potential to engage citizens and non-related adults in promoting the well-being of children where they can take a personal interest and become engaged. National or State level data may be too far removed from the experience of daily living to engage citizens. Small area indicators, then, may be seen as enhancing civic engagement around concerns for children's well-being. 